\title{
The Impact of Rate Regulation on Claims: Evidence From MASSACHUSETTS AUTOMOBILE INSURANCE
}

\author{
Richard A. Derrig \\ Sharon Tennyson
}

\begin{abstract}
The article tests the hypothesis that insurance price subsidies created by rate regulation lead to higher insurance cost growth. The article makes use of data from the Massachusetts private passenger automobile insurance market, where cross-subsidies were explicitly built into the rate structure through rules that limit rate differentials and differences in rate increases across driver rating categories. Two approaches are taken to study the potential loss cost reaction to the Massachusetts cross-subsidies. The first approach compares Massachusetts with all other states while controlling for demographic, regulatory, and liability coverage levels. Loss cost levels that were about 29 percent above the expected level are found for Massachusetts during years 1978-1998, when premiums charged were those fixed by the state and included explicit subsidies for high-risk drivers. A second approach considers changing cost levels across Massachusetts by studying loss cost changes by town and relating those changes to subsidy providers and subsidy receivers. Subsidy data based on accident year data for 1993-2004 show a significant and positive (relative) growth in loss costs and an increasing proportion of high-risk drivers for towns that were subsidy receivers, in line with the theory of underlying incentives for adverse selection and moral hazard.
\end{abstract}

\section{INTRODUCTION}

Rate regulation is widely practiced in insurance markets. In many U.S. states an important goal of insurance rate regulation is to reduce price variation across purchasers, and specifically to reduce price levels for high-risk purchasers. For example, some state regulations place limits on risk classes, restrict price differences across consumers, and restrict insurers' ability to deny coverage to high-risk purchasers to achieve these goals. These features of rate regulation may lead to price subsidies to insurance purchasers

Richard A. Derrig is with Opal Consulting, LLC; e-mail: richard@derrig.com. Sharon Tennyson is with the Department of Policy Analysis and Management, Cornell University; e-mail: st96@cornell.edu. The authors are grateful for the historical data and assistance provided by the Automobile Insurers Bureau, especially Kim A. Barber, William Scully, and Eilish Browne. An anonymous referee and seminar participants at Temple University, Wharton School of the University of Pennsylvania, University of Texas, and the American Risk and Insurance Association meetings provided helpful comments. This article was subject to double-blind peer review. 
financed from insurance company capital, and/or to price cross-subsidies from low-risk purchasers to high-risk purchasers.

Regulatory price distortions in competitive insurance markets may produce undesirable consequences due to incentive distortions that are created. For example, low-risk consumers who are charged higher prices in order to finance cross-subsidies to highrisks may be less likely to purchase insurance and to reduce participation in insured activities. These adverse selection effects will lead to a higher proportion of high-risk consumers and a higher proportion of insurance purchased by high-risks (Harrington and Doerpinghaus, 1993). In addition, because price subsidies reduce the links between insurance risk and insurance prices, all consumers face reduced incentives for loss prevention and safety investments due to moral hazard (Shavell, 1982). Another form of moral hazard created by insurance price subsidies is the reduced disincentives to file fraudulent insurance claims, if premium charges for additional claims or for high claim costs are artificially reduced by regulation. If insurers do not face the full profit or loss effects of claims-due to a residual market mechanism for insuring high-risks, for example-insurers may also face inadequate incentives to reduce loss costs (Blackmon and Zeckhauser, 1991). These combined adverse selection and moral hazard effects of insurance price subsidies lead to efficiency losses in the insurance market and will lead, in theory, to higher insured losses and thus to higher insurance prices in the long run. This article explores the economic importance of this hidden cost of insurance rate leveling.

The analysis makes use of data from the Massachusetts private passenger automobile insurance market, a state with unique regulatory characteristics. During the period of study, insurance prices in this market were determined annually through a state hearing process, and the state-determined rate grid formed the basis for pricing by all insurers in the state. ${ }^{1}$ Throughout portions of the study period, state-set rates produced lower than normal rates of return for insurers, leading to subsidies from insurer capital (Derrig, 1993). Beginning in 1978, cross-subsidies across driver groups were also explicitly built into the rate structure through rules that limit rate differentials and differences in rate increases across driver rating categories. Price subsidies are thus a hallmark of the Massachusetts regulatory system, providing an ideal venue for the study.

We conduct two distinct sets of analysis to present evidence on the relationship between price subsidies and insurance costs. In the first analysis, annual state-level data on loss costs per insured car for Massachusetts are compared to those in other states during the time period 1972-1998. This analysis uses variation in Massachusetts' regulations over time to demonstrate that cross-subsidies lead to unusually high loss costs in the state. The empirical results show that loss costs are significantly higher in Massachusetts after the cross-subsidy system is introduced (in 1978) but not before, and that the Massachusetts cost differential decreases during the 1990s after the state passed an insurance reform law (1989) and established an insurance fraud bureau (1991). ${ }^{2}$ These reforms eventually

\footnotetext{
${ }^{1}$ State-set Massachusetts private passenger automobile insurance rates were discontinued after 30 years as of April 1, 2008, replaced by a system of managed competition (Burnes, 2007).

${ }^{2}$ See Weisberg and Derrig (1992) for the effects of the tort reform, Derrig (1997) for the effects of the auto property reform, and Derrig et al. (2006) and Johnston (2009) for the more recent effects of the Insurance Fraud Bureau.
} 
led to lower loss costs and by 1996 insurers began to offer premiums to the lowest risk drivers that were below those set by the state (see Table 3 later in this article).

In order to more directly test the hypothesis that price cross-subsidies contribute to cost growth, we undertake a second analysis using data on loss experience for Massachusetts towns from the years 1993-2004. This analysis makes use of the variation in average premium subsidies across towns to identify the effects of subsidies on loss cost growth. The empirical results show that loss cost growth is significantly higher among towns in which the average driver receives a premium subsidy and that loss cost growth is positively and significantly related to the size of the premium subsidy.

The study adds to the growing empirical literature relating rate regulation to increases in insurance loss costs. Recent studies of automobile insurance by Weiss et al. (2010) and Regan et al. (2008) find that states imposing rate regulation experience significantly higher average loss costs and insurance claim frequency, and that more stringent regulation in a state is associated with a larger positive impact on losses and claim frequency. These results are obtained from panel data estimates using state-level data from all 50 states and controlling for other state characteristics and a state's endogenous choice of regulation.

An earlier study by Tennyson et al. (2002) provides evidence on automobile insurance regulation in Massachusetts specifically. Comparing Massachusetts annual state-level data on loss costs for the period 1980-1998 with those in other states, the authors find that costs are higher in Massachusetts than in other states. Regression analysis to control for state characteristics does not eliminate the finding, suggesting that the higher costs are due to rate regulation. Grace et al. (2002) provide a case study of the impact of automobile insurance regulation in South Carolina, another state that has experienced stringent rate regulation. Using a panel of county-level data, they find that automobile insurance loss cost growth is higher in counties that have a larger proportion of drivers insured through the involuntary market. Because premium subsidies should lead insurers to relegate more drivers to the residual market, these findings provide suggestive evidence that premium subsidies lead to higher insurance cost growth.

Similar results have been found in workers compensation insurance. Harrington and Danzon (2000) analyze a panel of annual state-level data on workers' compensation insurance for years 1984-1990 and find that regulatory suppression of prices leads to higher rates of cost growth in a state. In a study using data by individual rating classes from eight states for the period 1985-1991, Danzon and Harrington (2001) find that workers compensation loss cost growth is higher for classes with a larger proportion of risks insured in the involuntary (subsidized) market

Our study provides a more direct analysis of the relationship between regulatory premium subsidies and insurance costs than has been possible previously. Taking advantage of the explicit and transparent system of premium cross-subsidies under Massachusetts regulations, we estimate the effects of the subsidies by comparing loss cost levels in Massachusetts to those in other states before and after the subsidies are introduced. In addition, we use town-level data from within Massachusetts to examine the effect of subsidies on cost growth by comparing changes in loss costs and risk characteristics in towns that receive subsidies to those that do not. 


\section{TABLE 1}

Major Regulatory Changes, 1970-2007 Massachusetts Private Passenger Automobile Insurance

\begin{tabular}{ll}
\hline Year & \multicolumn{1}{c}{ Regulation } \\
\hline 1971 & No-fault auto insurance effective \\
1975 & State rate setting extended to all auto coverages \\
1977 & Competitive rate setting allowed \\
1978 & State rate setting reinstituted \\
1989 & Automobile insurance reform law effective \\
1991 & Insurance fraud bureau began operation \\
1996 & Competitive discounts and deviations begin at $-7.4 \%$ \\
2006 & Competitive discounts and deviations stabilize at $-1.7 \%$ \\
2007 & Competitive rate setting allowed January 4,2008 \\
\hline
\end{tabular}

The remainder of the paper is organized as follows. "The Massachusetts Automobile Insurance Regulation" section describes the regulated Massachusetts auto insurance system in more detail and documents the extent of premium subsidies. "Regulation and Loss Cost Growth in Massachusetts" develops the theoretical arguments regarding incentive effects of rate regulation and discusses prior research on the impact of insurance regulation and premium subsidies. The section "Relating Premium Subsidies to Loss Cost Growth" introduces the Massachusetts town-level data and presents results of analysis of those data. The "Conclusion" summarizes and discusses the implications of our findings.

\section{Massachusetts Automobile Insurance Regulation}

\section{Regulated Premium Subsidies}

In Massachusetts during the period of study, regulated private passenger automobile insurance rates were determined annually by the state insurance commissioner as the outcome of a public hearing process. ${ }^{3}$ The rates determined through the hearing process were to be charged by all firms writing in the state-irrespective of differences in operating costs or loss experience-unless an insurer obtained approval from the insurance commissioner to charge lower rates. ${ }^{4}$ Massachusetts has regulated automobile insurance rates in this way since 1927, but the regulatory features of primary interest to this article took shape in the late 1970s. Table 1 lists the timeline of major developments in the regulatory environment in Massachusetts.

\footnotetext{
${ }^{3}$ The commissioner's rates are subject to review only by petition to the Massachusetts Supreme Court, a step taken on rare occasions by the subject insurers. Thus, the Decision Rates were the rates actually charged in the rate years 1978-1995.

${ }^{4}$ Historically, such deviations were not common; however, most insurers sought significant rate deviations for selected groups of drivers in 1996-2004 as shown in Table 3.
} 
The regulatory features of interest to this article were introduced in Massachusetts after a brief experiment with a more competitive system in $1977 . .^{5}$ In that year legislation introduced file-and-use rate regulation, which allowed insurers to set their own rates subject to light regulatory review. The new system led to dramatic increases in premiums and reduced insurance availability for some drivers, producing a record number of consumer complaints to the Division of Insurance (Stone, 1977). In response, the state returned to the state-made rates, and new legislation and regulatory decisions imposed even further state controls over pricing. ${ }^{6}$

The new legislation prohibited premium surcharges to policyholders insured through the residual market facility. Insurance department regulations mandated a common set of rating territories and driver rating classes for all insurers. Rating territories were determined by town and the assignment of towns to territories was determined through a periodic hearing process. Only nine driver rating classes were allowed, with drivers classified only by driving experience, drivers' training, and use of car. Age, gender, and marital status were specifically prohibited from use as rating variables (Mass GL c. $175 \mathrm{E}, \mathrm{s} 4(\mathrm{~b}))$. These restrictions produce a far coarser rate matrix than used in other states' automobile insurance markets, leading to cross-subsidies in rates across drivers. ${ }^{7}$

Additional cross-subsidies were built into the rates through a systematic leveling process known as tempering and capping. Tempering restricts the differences in average rate levels across the class-territory rating cells. Capping restricts the average annual increase in rates for any rating cell to be no more than a prespecified percentage above the average statewide rate increase. Capping thus restricts the change in average rate levels over time for each rating category, reinforcing the cross-subsidies generated by tempering. A final set of interclass rate constraints was applied within each territory to assure that the lower risk classes do not pay more than a given percentage of the rate paid by higher risk classes. The application of these constraints introduced additional, sometimes substantial, cross-subsidies across drivers. ${ }^{8}$

This complex set of restrictions produced significant variation in premium charges relative to those based on costs alone. Some drivers receive substantial premium subsidies, with the remaining drivers paying relatively smaller premium increases. Table 2 summarizes the direction and extent of premium subsidies received and premium subsidies paid, using data for $2004 .^{9}$ The table reports the average premium, average subsidy (or surcharge) amount and the percent of class-territory rating cells that are subsidized for

\footnotetext{
${ }^{5}$ See Derrig (1993), Yelen (1993), Rottenberg (1989), and Tennyson et al. (2002) for more discussion of the history and process of Massachusetts regulation. Details on the current competitive market regulations are available at the Web site of the state of Massachusetts http://www.mass.gov/.

${ }^{6}$ State-set rates were reintroduced due to a provision in the law that allows the insurance commissioner to hold an annual hearing to determine whether competition is feasible, and to impose state-set rates if it is not. In every year 1978-2006, competition was found not to be viable and state-set rates were imposed.

${ }^{7}$ For example, Finger (2006) notes that the standard industry classification plan contains 217 driver classes in the voluntary market.

${ }^{8}$ For 2007 Boston Compulsory Rates, the interclass constraints generated half of the average subsidy of 17.6 percent (AIB, Actuarial Notice $07-1$, p. 2).

${ }^{9}$ The premiums paid by each individual driver vary from the class-territory average due to experience rating adjustments based on accident experience, the type of car driven, and other
} 


\section{TABLE 2}

Direction of Subsidies by Driver Class and Territory, Compulsory Insurance Coverage, 2004

\begin{tabular}{llrrr}
\hline & & $\begin{array}{c}\text { Experienced } \\
\text { Classes }\end{array}$ & $\begin{array}{c}\text { Inexperienced } \\
\text { Classes }\end{array}$ & Other Classes \\
\hline Non-Boston territories & Average premium & $\$ 527.15$ & $\$ 1,220.54$ & $\$ 500.67$ \\
& Average subsidy & $-\$ 26.00$ & $\$ 138.29$ & $-\$ 46.43$ \\
& Cells subsidized (\%) & $12.5 \%$ & $42.7 \%$ & $6.3 \%$ \\
Boston territories & Average premium & $\$ 813.33$ & $\$ 1,434.04$ & $\$ 751.98$ \\
& Average subsidy & $\$ 253.77$ & $\$ 520.09$ & $\$ 32.30$ \\
& Cells subsidized (\%) & $64.7 \%$ & $72.7 \%$ & $36.4 \%$ \\
\hline
\end{tabular}

Source: Authors' calculations using data from Actuarial Notice 04-1, Automobile Insurers Bureau of Massachusetts (AIB) (2004).

compulsory insurance coverage. The data show that substantial premium subsidies are received by some drivers and paid for by the remaining insured drivers.

Boston drivers and inexperienced drivers are those most likely to receive a subsidy, but some proportion of drivers in every rating cell receive a subsidy. ${ }^{10}$ Within Boston, 72.7 percent of inexperienced driver rating cells, 64.7 percent of experienced driver rating cells, and 36.4 percent of business cells receive a subsidy. Outside of Boston, 42.7 percent of inexperienced driver rating cells receive a subsidy. In contrast, only 12.5 percent of experience driver cells and 6.3 percent of other driver cells outside of Boston receive a subsidy. Both experienced and inexperienced Boston drivers receive substantial premium subsidies (averaging \$253.77 and \$520.09, respectively), while Boston's other classes receive only a modest subsidy (\$32.30). Although subsidy amounts vary across years, these general patterns of cross-subsidies given and received remain stable.

It is natural to ask how the state can sustain an auto insurance market under the regulations described here. Several additional regulations promote the continued supply of insurance in the market. Access to insurance for high-risk drivers is protected by restrictions on insurers' ability to refuse insurance, cancel a policy, or charge different rates for residual market risks. There are also strong restrictions placed on insurers' rights to

factors. Experience rating adjustments are applied through the revenue-neutral Safe Driver Insurance Plan (SDIP), which allows for discounts and surcharges to bodily injury liability (BIL), property damage liability (PDL), and collision rates based upon one's recent driving record. The state also allows premium discounts for antitheft devices, airbags, low mileage, multiple cars, or use of public transit. These adjustments are applied as percentage changes to the premium but are relatively modest. The state determines experience rating adjustments and other adjustments, which are subject to prior approval regulation. Premium surcharges to drivers insured through the state's residual market facility are prohibited.

${ }^{10}$ The number of drivers receiving subsidies or paying surcharges differs from the number of insured vehicles in the rating cells, due to cross-subsidies across drivers within class-territory rating cells. 
exit the automobile insurance market. An insurer wishing to withdraw from the market must receive regulatory approval and must pay substantial penalties in order to exit the market (Yelen, 1993). Finally, insurance demand is bolstered by a strong compulsory insurance law.

Nonetheless, previous studies have documented a number of distortions to the Massachusetts' market that arise due to regulation (Rottenberg, 1989; Derrig, 1993; Tennyson, 1997; Tennyson et al., 2002). Most notably, these studies have found that the supply side characteristics of the Massachusetts automobile insurance market differ from those in comparable state markets, with far fewer insurance providers ${ }^{11}$ and fewer national insurers in the state. Residual market size is also greater in Massachusetts, providing another indicator of lack of insurance availability. And movement toward lower cost distribution systems has been much slower there than in other automobile insurance markets.

\section{Premium Subsidies and Driver Incentives}

If insurance premiums reflect the expected marginal costs of coverage, consumers have appropriate information on which to base their decisions about insurance purchase and also their decisions to purchase a car, and/or to drive (Harrington and Doerpinghaus, 1993). However, consumers who receive premium subsidies face less than the true expected marginal cost of their decisions with respect to insuring and driving decisions and will be more likely to own a car, to drive, and to purchase more insurance. Consumers who pay premium overcharges will have the opposite response, tending to be less likely to drive and to purchase less insurance. Previous studies in automobile insurance find that insurance purchase decisions are sensitive to price cross-subsidies. Dahlby (1983, 1992) finds that restrictions on gender-related pricing in Canada lead young female (lower-risk) drivers to reduce insurance purchase relative to young male (higher-risk) drivers. The collective impact of these decisions will lead to higher average costs of insurance, as more high-risk drivers participate in the insurance pool and fewer lowrisk drivers participate.

Drivers also make choices about the amounts and types of driving and other actions that are correlated with expected loss costs. ${ }^{12}$ These choices will also be distorted by subsidies, because subsidies reduce the penalties for risk taking. In Massachusetts, higher premium charges due to higher accident costs of any one driver will be partly shared by the driver under a Safe Driver Insurance Plan (SDIP) ${ }_{1}^{13}$ partly across all members of the class-territory rating cell, and partly by all subsidy-paying drivers in the remainder of the Commonwealth. Furthermore, policies cannot be canceled based on loss or accident experience. Risky choices may move a driver into the residual market but at no premium differential. These regulatory restrictions may increase the risky choices of all drivers. As

\footnotetext{
${ }^{11}$ Only 19 (nonspecialty) insurers operated in the Massachusetts private passenger automobile insurance in 2006.

${ }^{12}$ See Brockett and Golden, (2007) for a discussion of risky behavior by drivers and its relation to credit scores as a proxy measurement of that risk.

${ }^{13}$ The Massachusetts Safe Driver Insurance Plan sets forth differentials within each rate class based upon at-fault accidents and traffic violations.
} 
a result, average loss costs are predicted to be higher under the Massachusetts regulatory system than otherwise.

Perhaps as important, there may be an additional upward shift in insured claims and loss costs due to the greater incentives for claims filing introduced by the rate structure. Consumers consider the marginal costs and the marginal benefits when deciding whether to file a claim. The restrictions on policy cancellation, the relatively small premium penalties for high losses, and the tempering of rate increases across time imply that the future adverse consequences of filing a claim or of filing many claims are lessened. This may increase the propensity of consumers to file claims, whether legitimate claims, or fraudulent or exaggerated claims. ${ }^{14}$ Under Massachusetts law insurers may cancel a policy due to fraud, but the fraud must be proven, which may be costly and difficult. In a competitive market each individual insurer's fraud detection efforts may be less than socially optimal, due to the inability to commit to an optimal auditing strategy (Picard, 1996). In Massachusetts this problem may be exacerbated during periods when a large proportion of drivers are insured in the residual market, due to the pooling of residual market losses across insurers (Blackmon and Zeckhauser, 1991). These forces suggest that there will be a greater incidence of fraudulent claiming in Massachusetts.

The prediction of fraudulent claim behavior was observed soon after the 1988 Reform Law provision that raised the monetary threshold to file a tort claim from $\$ 500$ to $\$ 2,000$ in claimed medical bills. Weisberg and Derrig (1992) document the increase in numbers and intensity of medical provider visits with the result being a much largerthan-anticipated 1989 proportion of auto injury claims with medical bills in excess of $\$ 2,000$, the new tort threshold. More recently, Derrig et al. (2006) discuss auto injury claims with the appearance of fraud and/or buildup ${ }^{15}$ both countrywide through the Insurance Research Council (IRC) Study of 2002 Claims and in Massachusetts through the developments in the town of Lawrence. In Lawrence, Insurance Fraud Bureau (IFB) activities reduced injury claims per 100 accidents (PDL claims) from 141 in 2002 to 60 in 2004 and claim payments from \$48.6 million in 2002 to \$19.8 million in 2004. Granted, Lawrence was an exceptional case identified as far back as 1991 (Weisberg and Derrig, 1991), but reductions on a lesser scale in other towns have been realized by IFB efforts since 2002.

We now turn to formal empirical analysis of data from the Massachusetts private passenger automobile insurance market to test for the hypothesized link between regulated premium subsidies and loss cost growth. State-level data are used to compare

\footnotetext{
${ }^{14}$ In addition, the no-fault compensation system increases the marginal benefits of building up bodily injury claims. First-party insurance for automobile related injuries is mandatory in Massachusetts under PIP coverage, which pays a maximum of $\$ 8,000$ in losses, which can be offset by up to $\$ 6,000$ through private health insurance. However, injured parties may be eligible for compensation under bodily injury liability (BIL) in addition to PIP if their medical expenses exceed $\$ 2,000$. BIL claimants may be compensated for medical and wage losses, plus "pain and suffering." This provides significant incentives for fraudulent BIL claiming, and the medical expense threshold for BIL claiming provides significant incentives for PIP claims buildup (Weisberg and Derrig, 1991, 1992; Cummins and Tennyson, 1992, 1996).

15 "Buildup" is the term of art for excessive treatment for the injury (if any) sustained in an auto accident with treatment usually provided by a chiropractor or physical therapist.
} 


\section{FIGURE 1}

Average Annual Loss Costs per Insured Car, Massachusetts Versus Other States

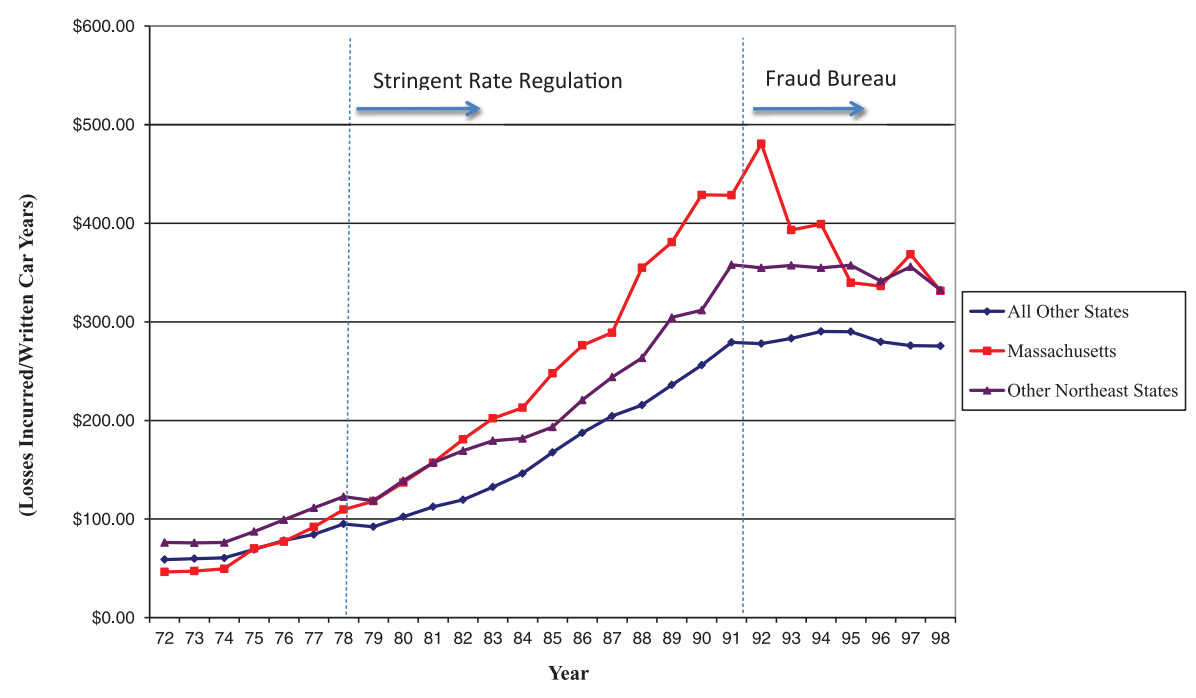

Massachusetts loss costs with those that would be predicted in the absence of the rate regulations. Massachusetts' town-level data are used to examine whether cost growth is higher in towns that receive larger premium subsidies.

\section{Regulation and Loss Cost Growth in Massachusetts}

We use a panel of annual state-level data from Massachusetts and the other 49 states for the time period 1972-1998. The data encompass the time period before new rate regulations were in force, the period during the enforcement of the most stringent rate regulations, and a period during which rate regulatory stringency was relaxed.

Figure 1 plots Massachusetts annual loss costs over the time period 1972-1998, along with the average losses for all other states and average losses for all other states in the New England census region. The loss costs reported in the figure are statewide average liability losses per insured car, constructed as total liability losses incurred divided by number of written car years. The liability losses are those reported in the insurers' annual statements, as compiled by the National Association of Insurance Commisioners (NAIC), and are obtained from A.M. Best's Aggregates and Averages. Liability loss data include those paid under all automobile bodily injury insurance, including bodily injury liability (BIL), first-party personal injury protection (PIP) in no-fault states, medical payments, and uninsured/underinsured motorist coverages, along with losses incurred under property damage liability (PDL) coverage. Losses not included in the liability data series are first-party property damage losses paid under collision and comprehensive insurance coverages. Liability losses are used in this comparison because liability coverages are compulsory in most states. Thus, there is expected to be less variation due to differences in insurance purchase in automobile liability insurance losses than in total automobile insurance losses.

Figure 1 shows a striking difference between Massachusetts loss costs and those of other states after the introduction of cross-subsidy regulations, and virtually no difference 


\section{TABLE 3}

Historical Summary of Industry Discounts/Deviations

\begin{tabular}{lcc}
\hline Year & Average Discount & Annual Change in Discount \\
\hline 1996 & $-7.4 \%$ & \\
1997 & $-9.2 \%$ & $-1.8 \%$ \\
1998 & $-9.2 \%$ & $+0.0 \%$ \\
1999 & $-6.5 \%$ & $+2.7 \%$ \\
2000 & $-5.5 \%$ & $+1.0 \%$ \\
2001 & $-3.0 \%$ & $+2.5 \%$ \\
2002 & $-2.2 \%$ & $+0.8 \%$ \\
2003 & $-1.9 \%$ & $+0.3 \%$ \\
2004 & $-1.7 \%$ & $+0.2 \%$ \\
2005 & $-1.8 \%$ & $-0.1 \%$ \\
2006 & $-1.7 \%$ & $+0.1 \%$ \\
2007 & $-1.7 \%$ & $+0.0 \%$ \\
\hline
\end{tabular}

Source: Automobile Insurers Bureau of Massachusetts.

between Massachusetts and other states prior to $1977 .{ }^{16}$ The loss cost gap appears just at the time the more stringent rate regulations are enacted in Massachusetts. The greatest loss cost gap appears in the mid-1980s, a period when regulators suppressed insurance prices on average in addition to enforcing price cross-subsidies (Derrig, 1993). The distance between Massachusetts loss costs and those other states is reduced in the 1990s, at a time when the state introduced antifraud measures and when regulatory stringency was relaxed sufficiently that insurers offered discounted rates to select low-risk drivers. Table 3 reports the average annual percentage discounts offered by insurers, subject to prior approval, beginning in 1996.

Of course, other features of the state may account for the difference in insured loss costs. Massachusetts is a largely urban state with high traffic density, which may contribute to higher rates of accidents. The state population also has high per capita income and high cost of living, which may contribute to higher costs per claim. Moreover, the increase in relative loss costs in Massachusetts in the early 1990s coincides with an increase in the maximum first-party PIP compensation (from $\$ 2,000$ to $\$ 8,000$ ) and compulsory BIL limits (from $\$ 10,000 / \$ 20,000$ to $\$ 20,000 / \$ 40,000$ per person and per accident, respectively). This pattern reinforces the idea that factors such as coverage amounts must be controlled for when comparing loss costs across states. ${ }^{17}$

${ }^{16}$ Loss costs for 1977 were incurred under a mixed regulatory system that began as open competition then collapsed under an average 14.5 percent increase and ended with a rate rollback for 1977 and return to fix and establish rates for 1978 (Burnes, 2007).

${ }^{17}$ Weisberg and Derrig (1992) argue that this change also increased incentives for claims exaggeration, due to the need to exceed the threshold in order to become eligible to file a bodily 


\section{Regression Analysis}

To further explore whether Massachusetts loss costs are higher than expected we estimate a regression model using 1972-1998 annual loss cost data from 50 states, including control variables for time-varying state characteristics as well as state fixed effects. The methodology for modeling the effect of regulation is to examine whether the difference between Massachusetts' loss costs and those of other states is significantly different before and after the rate regulations that introduced substantial price cross-subsidies in Massachusetts.

Because there are many other determinants of loss costs at the state aggregate level, the empirical model includes state characteristics as control variables. The empirical model takes the basic form:

$$
\begin{aligned}
L_{s t}= & \beta_{0}+\beta_{1} \text { CSYears }_{t}+\beta_{2} \text { MA }_{s} \text { CSYears }_{t}+\beta_{3} \text { StateRegs }_{s t}+\beta_{4} \text { StateRegs }_{s t} \text { CSYears }_{t} \\
& +\delta X_{s t}+a_{s}+\varepsilon_{s t},
\end{aligned}
$$

where subscript $s$ denotes state and $t$ denotes year, the term $a_{s}$ represents a state fixed effect, and the term $\varepsilon_{s t}$ is a stochastic error term. Including state fixed effects implies that we are testing for differences in Massachusetts loss costs under the cross-subsidy regulation relative to average loss costs in the state over the sample period. In the reported estimates, the standard errors are corrected to allow for heteroskedasticity and for correlation within each state across time (Bertrand et al., 2004).

The dependent variable $L_{s t}$ is the logarithm of statewide average liability losses per car. The variable CSYears $t$ is an indicator variable set equal to one in the years during which cross-subsidy regulation was imposed in Massachusetts (i.e., beginning in 1978), and set equal to zero in other years. The impact of subsidies in Massachusetts is identified by including the interaction of a Massachusetts dummy variable $\left(M A_{s}\right)$ with the crosssubsidy years variable: $M A_{s} C S Y e a r s_{t}$. If premium cross-subsidies in Massachusetts are a significant determinant of higher loss costs in the state, then-after controlling for other determinants of losses-we expect to find a significant increase in loss cost differences in Massachusetts during the regulatory periods denoted by CSYears, ${ }_{\text {, }}$ and thus a significantly positive value for the coefficient $\beta_{2}$. Including the dummy variable CSYears $t_{t}$ for the years in which Massachusetts cross-subsidy regulation occurs means that we are testing for differences in Massachusetts loss costs relative to any nationwide effects on auto insurance loss costs that occur in those years.

StateRegs $s_{s t}$ is a vector of variables reflecting each state's legal and regulatory environment for auto insurance in state $s$ and year $t$; included are indicators of a state's use of rate regulation and no-fault auto insurance. Indicators of states' rate regulation regimes in each year are obtained from Harrington (2002). Indicators of no-fault regimes by state and year are obtained from the Insurance Information Institute. Massachusetts has both rate regulation and no-fault throughout the sample period, and so we include these variables and interact them with CSYears. This specification means that the interaction term $M A_{s} \mathrm{CSY}_{\text {ears }}$ estimates the effects of the cross-subsidy regulations in Massachusetts relative to other rate-regulated and no-fault states during those years.

injury liability claim. Their analysis shows that PIP claim amounts cluster at the value of the tort threshold. 
The variable denoted $X_{s t}$ is a vector of other time-varying state characteristics that are expected to affect average automobile liability insurance loss costs. These include traffic density, defined as total vehicle miles driven divided by total miles of roadway in the state; per capita income; the statewide average cost per day of hospital stay; the automobile fatality rate, defined as the number of automobile fatalities per mile driven; and an indicator for whether automobile insurance is compulsory. ${ }^{18}$ All variables except the compulsory insurance indicator are entered in the model in log form.

We also recognize that differences in loss costs across states and years will be affected by differences in insurance purchase amounts. For example, the average insurance coverage limits may vary across states and years, and states with no-fault insurance may provide different coverage limits for compulsory (or optional) first-party PIP limits. To partially control for these differences, our models include the minimum required coverage limits for BIL and PDL coverages in each state and year, and the maximum PIP limits in no-fault (and add-on) states. ${ }^{19}$

Finally, in some model specifications the lagged statewide average automobile liability loss ratio relative to the countrywide average loss ratio is included as an additional regressor. ${ }^{20}$ This variable will capture the effects of insurance market conditions in both rate-regulated and unregulated states, including the effects of regulatory suppression of average insurance prices in rate-regulated states. The variable reduces the likelihood that other effects of rate regulation that contribute to excessive loss costs in Massachusetts are mistakenly attributed to the effects of price cross-subsidies.

Table 4 reports summary statistics of the variables included in the state regression models. The data used in estimation cover the years 1973-1998 because some specifications include the lagged (relative) loss ratio. The table reports the mean and standard deviation of each variable for the full set of states and for Massachusetts alone. The data confirm the conclusion from Figure 1 that average loss costs in Massachusetts are higher than the national average. The data also reveal that traffic density, per capita income, and costs of medical care-factors that could contribute to automobile loss costs-are higher in Massachusetts. Automobile fatality rates are lower than the national average in Massachusetts. As noted previously, Massachusetts is a no-fault state and has a compulsory insurance law; however, Massachusetts' mandatory coverage limits were lower than the national average.

\footnotetext{
${ }^{18}$ Data on miles driven, miles of roadway, and traffic fatalities are obtained from the U.S. Department of Transportation. Data on costs of hospital stays are obtained from relevant editions of the U.S. Statistical Abstract. Data on registered automobiles is obtained from the Automobile Insurance Plans Services Office (AIPSO). Data on states' compulsory automobile insurance laws are obtained from the Insurance Information Institute (III).

${ }^{19}$ These data are obtained from the III.

${ }^{20}$ Loss ratios are constructed as statewide liability losses (as defined in the text) divided by statewide premiums earned. The countrywide average loss ratio is the simple average of statewide loss ratios. Estimation results are similar when the lagged statewide average automobile liability loss ratio is included directly (rather than the loss ratio relative to the countrywide average).
} 


\section{TABLE 4}

Summary Statistics, Annual State-Level Data, 50 States 1973-1998

\begin{tabular}{lrrrrrrr}
\hline & \multicolumn{2}{c}{ All Other States } & & \multicolumn{2}{c}{ Massachusetts } & \\
\cline { 2 - 3 } Variable & Mean & S.D. & & Mean & S.D. & S-test \\
\hline Losses per insured car & 179.68 & 3.08 & & 250.34 & 26.65 & $3.23^{* * *}$ \\
Rate regulation dummy & 0.59 & 0.01 & & 1.00 & 0.00 & $4.27^{* * *}$ \\
Lag(state LR/national LR) & 1.00 & 0.00 & & 0.96 & 0.02 & $-2.04^{* *}$ \\
No-fault dummy & 0.26 & 0.01 & & 1.00 & 0.00 & $8.51^{* * *}$ \\
Add-on dummy & 0.19 & 0.01 & & 0.00 & 0.00 & $-2.49^{* * *}$ \\
Person minimum limit (000) & 18.66 & 0.19 & & 12.69 & 0.84 & $-4.45^{* * *}$ \\
Property minimum limit (000) & 9.77 & 0.15 & & 5.00 & 0.00 & $-4.63^{* * *}$ \\
PIP coverage limit & 13,765 & 1,314 & & 4,077 & 571 & -1.05 \\
Addon coverage limit & 941.13 & 73.32 & & 0.00 & 0.00 & $-1.83^{*}$ \\
Compulsory insurance & 0.41 & 0.01 & & 1.00 & 0.00 & $6.13^{* * *}$ \\
Traffic density & 0.52 & 0.01 & & 1.21 & 0.04 & $8.91^{* * *}$ \\
Average cost of hospitalization & 504.68 & 9.01 & 636.43 & 75.02 & $2.06^{* *}$ \\
Per capita income & 13,974 & 187 & & 17,185 & 1,709 & $2.43^{* *}$ \\
Auto fatalities per mile driven & 0.03 & 0.00 & & 0.02 & 0.00 & $-3.85^{* * *}$ \\
\hline
\end{tabular}

Note: ${ }^{* * *}$ indicates Massachusetts mean is significantly different from other states' average at the 1 percent confidence level, ${ }^{* *}$ indicates significant a difference at the 5 percent confidence level, and ${ }^{*}$ indicates significant difference at the 10 percent confidence level. All are two-sided tests. Source: Authors calculations from state-level data.

\section{Estimation Results}

The estimation results are shown in Table 5. We estimate models using two alternative definitions of the regulated cross-subsidy period. The first model defines this to be years 1978-1998, while the second model defines the cross-subsidy period to be years 19781995 since insurer discounting of premiums for the safest drivers in 1996-1998 may have reduced the effect of regulated cross-subsidies. For each model we estimate two alternative specifications, a basic specification and one in which the lagged (relative) automobile liability loss ratio is included as a regressor. The first two columns of the table report the estimates obtained when the cross-subsidy years are defined as 19781995 and the second two columns report the estimates when the cross-subsidy years are defined as 1978-1998.

The estimated models demonstrate a good fit, with adjusted $R^{2}$ values around 88 percent. Many of the control variables are significant and have the expected signs. A positive relationship is found between minimum compulsory coverage amounts and loss costs, and maximum PIP damages and average liability loss costs. Higher traffic density, hospitalization costs, and per capita income are also associated with higher average liability costs while higher traffic fatalities per mile are associated with lower average loss costs per car. Contrary to expectations, rate regulation in the average state (as 


\section{TABLE 5}

Regression Analysis of Statewide Annual Average Liability Losses per Car, 1973-1998

\begin{tabular}{|c|c|c|c|c|}
\hline \multicolumn{5}{|c|}{ Dependent Variable = Ln(Liability Losses/Written Car Years) } \\
\hline \multirow[b]{2}{*}{ Explanatory Variable } & \multicolumn{2}{|c|}{ CS Years 1978-1998 } & \multicolumn{2}{|c|}{ CS Years 1978-1995 } \\
\hline & Model 1 & Model 2 & Model 1 & Model 2 \\
\hline \multirow[t]{2}{*}{ MA $\times$ CS years } & $0.393^{* * *}$ & $0.256^{* * *}$ & $0.363^{* * *}$ & $0.260^{* * *}$ \\
\hline & 6.446 & 4.449 & 7.820 & 6.729 \\
\hline \multirow[t]{2}{*}{ Reg $\times$ CS years } & 0.108 & 0.086 & 0.033 & 0.016 \\
\hline & 1.606 & 1.358 & 0.850 & 0.452 \\
\hline \multirow[t]{2}{*}{ No-fault $\times$ CS years } & 0.000 & 0.058 & -0.005 & 0.017 \\
\hline & 0.007 & 1.064 & -0.136 & 0.536 \\
\hline \multirow[t]{2}{*}{ CS years dummy } & $-0.073^{*}$ & $-0.069^{*}$ & $0.061^{* *}$ & $0.070^{* * *}$ \\
\hline & -1.677 & -1.767 & 2.513 & 3.118 \\
\hline \multirow[t]{2}{*}{ Lag state LR/national LR } & & $0.657^{* * *}$ & & $0.657^{* * *}$ \\
\hline & & 6.815 & & 6.954 \\
\hline \multirow[t]{2}{*}{ Rate regulation dummy } & -0.087 & -0.056 & -0.013 & 0.010 \\
\hline & -1.530 & -1.070 & -0.294 & 0.265 \\
\hline \multirow[t]{2}{*}{ No-fault dummy } & 0.041 & -0.007 & 0.016 & -0.006 \\
\hline & 0.757 & -0.106 & 0.334 & -0.117 \\
\hline \multirow[t]{2}{*}{ Addon dummy } & 0.103 & $0.137^{*}$ & 0.078 & 0.114 \\
\hline & 1.146 & 1.949 & 0.792 & 1.522 \\
\hline \multirow[t]{2}{*}{ Person minimum limit } & $0.008^{* *}$ & $0.005^{*}$ & $0.008^{* *}$ & $0.006^{*}$ \\
\hline & 2.275 & 1.798 & 2.466 & 1.894 \\
\hline \multirow[t]{2}{*}{ Property minimum limit } & 0.007 & 0.007 & 0.007 & 0.007 \\
\hline & 1.404 & 1.565 & 1.364 & 1.523 \\
\hline \multirow[t]{2}{*}{ PIP maximum } & $0.006^{*}$ & $0.006^{* *}$ & $0.008^{* *}$ & $0.009^{* * *}$ \\
\hline & 1.715 & 2.257 & 2.262 & 3.437 \\
\hline \multirow[t]{2}{*}{ Add-on maximum } & 0.263 & 0.247 & 0.270 & 0.249 \\
\hline & 1.294 & 1.417 & 1.266 & 1.363 \\
\hline \multirow[t]{2}{*}{ Compulsory insurance } & -0.017 & -0.025 & -0.004 & -0.014 \\
\hline & -0.316 & -0.489 & -0.069 & -0.283 \\
\hline \multirow[t]{2}{*}{ Ln(traffic density) } & $0.168^{*}$ & $0.156^{*}$ & $0.230^{* *}$ & $0.230^{* *}$ \\
\hline & 1.865 & 1.859 & 2.258 & 2.459 \\
\hline \multirow[t]{2}{*}{ Ln(hospitalization cost) } & $0.324^{* * *}$ & $0.316^{* * *}$ & $0.268^{* * *}$ & $0.260^{* * *}$ \\
\hline & 2.843 & 2.699 & 2.692 & 2.592 \\
\hline \multirow[t]{2}{*}{ Ln(per capita income) } & $0.409^{* * *}$ & $0.412^{* * *}$ & $0.433^{* * *}$ & $0.437^{* * *}$ \\
\hline & 2.680 & 2.710 & 3.235 & 3.369 \\
\hline \multirow[t]{2}{*}{ Ln(auto fatalities per mile) } & $-0.119^{*}$ & $-0.160^{* *}$ & $-0.120^{*}$ & $-0.153^{* * *}$ \\
\hline & -1.742 & -2.533 & -1.875 & -2.591 \\
\hline
\end{tabular}


TABLE 5

(Continued)

\begin{tabular}{|c|c|c|c|c|}
\hline \multicolumn{5}{|c|}{ Dependent Variable $=$ Ln(Liability Losses $/$ Written Car Years) } \\
\hline \multirow[b]{2}{*}{ Explanatory Variable } & \multicolumn{2}{|c|}{ CS Years 1978-1998 } & \multicolumn{2}{|c|}{ CS Years 1978-1995 } \\
\hline & Model 1 & Model 2 & Model 1 & Model 2 \\
\hline \multirow[t]{2}{*}{ Intercept } & -1.298 & $-2.079^{* *}$ & -1.256 & $-1.991^{* * *}$ \\
\hline & -1.533 & -2.534 & -1.594 & -2.664 \\
\hline State fixed effects & Yes & Yes & Yes & Yes \\
\hline$R^{2}$ & 0.876 & 0.884 & 0.879 & 0.888 \\
\hline$N$ & 1,286 & 1,286 & 1,286 & 1,286 \\
\hline
\end{tabular}

Note: $T$-statistics appear below the coefficient estimates. ${ }^{* * *}$ indicates statistical significance at the 1 percent confidence level, ${ }^{* *}$ indicates the 5 percent confidence level, and $*$ indicates the 10 percent confidence level; all are two-sided tests. Coefficients for PIP and Addon maximum coverage amounts are multiplied by 10,000.

measured by the rate regulation dummy and the rate regulation dummy interacted with CSYears) is not associated with higher average liability loss costs. ${ }^{21}$

The estimates indicate that Massachusetts loss costs were significantly higher than expected during the period of cross-subsidy regulation, after controlling for other characteristics of the state insurance market. All four specifications show $M A_{s} \mathrm{CSYears}_{\tau}$ significant and positive at the 1 percent confidence level. The estimates when the lagged (relative) loss ratio is included in the model show Massachusetts experienced about 29 percent $(\exp (0.2560))$ or $\exp (0.2600))$ higher liability loss costs than in the overall U.S. market with the same demographics and liability coverage characteristics. ${ }^{22}$

To provide a year-by-year estimate of the effects of cross-subsidies on loss costs, an alternative model is estimated with a Massachusetts dummy variable interacted separately with each individual year during the cross-subsidy period rather than using a single

\footnotetext{
${ }^{21}$ Weiss et al. (2010) find a positive and significant relationship between rate regulation and average liability loss costs for the time period 1980-1998 when states' endogenous choice of rate regulation is accounted for.

${ }^{22}$ In contrast, the estimates when the lagged (relative) loss ratio is not included in the model show Massachusetts experienced 44 percent (exp0.363) to 48 percent (exp0.393) higher liability loss costs than the overall U.S. market, indicating a positive effect of other subsidies, such as rate suppression as a subsidy from the insurer's capital, in addition to the cross subsidies. At the suggestion of a referee, we also ran the models omitting the automobile fatality rate. According to these estimates (which include the lagged relative loss ratio) Massachusetts experienced 28 percent (exp0.247) to 32 percent (exp0.280) higher liability loss costs than the U.S. average.
} 


\section{FIGURE 2}

\section{Estimated Year-by-Year Excess Average Loss Costs, Massachusetts}

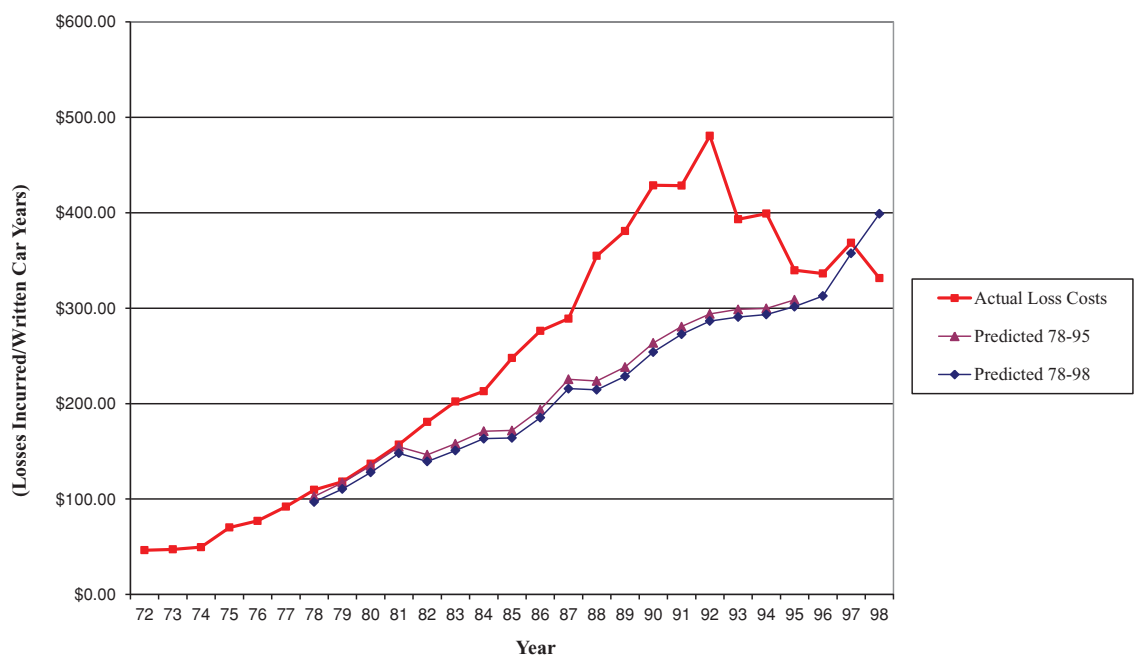

dummy variable for the entire cross-subsidy period. ${ }^{23}$ Using this approach we find loss costs in Massachusetts are significantly higher than would otherwise be predicted during most of the years of cross-subsidy regulation. Specifically, the estimated coefficients on the Massachusetts dummy variable are statistically significant and positive in 1978 and for all years 1982-1992; when the cross-subsidy years are 1978-1998, the estimated Massachusetts coefficient is also negative and statistically significant in the year 1998. Figure 2 shows the plot of estimated cross-subsidy effects in Massachusetts for each year, for both the 1978-1995 and 1978-1998 estimates, based on the models that include the lagged (relative) loss ratio. The figure compares the actual average loss costs per car in Massachusetts to those that would have been realized if the percentage effects obtained from the yearly dummy variable interactions were subtracted from actual costs. The difference between the actual cost line and the predicted cost line represents the estimated excess loss costs in each year.

The comparison shows that average liability loss costs in Massachusetts were about at the levels that would be expected in other comparable states for the regulated years 1978 through 1981. Beginning in 1982 and extending through 1995, however, actual average loss costs in Massachusetts were higher than would be expected in other comparable states, with the differences increasing over time. The difference between actual and predicted losses begins to decline after 1992 (about the time the IFB became operable). By 1996, when rate regulatory stringency had relaxed sufficiently that insurers began discounting below state-set rates for some drivers, actual losses were about at the level predicted for other comparable states.

\footnotetext{
${ }^{23}$ We thank Scott Harrington for suggesting this analysis. The full estimation results are available
} from the authors. 


\title{
Relating Premium Subsidies to Loss Cost Growth
}

The state-level data provide evidence that average loss costs are higher under the crosssubsidy regulations than would otherwise be expected in Massachusetts. However, even with the rich set of controls included in the estimated models these state-level cost differences provide only suggestive evidence of incentive distortions from premium subsidies. For example, it is possibile that the period of regulated cross-subsidies is associated with higher loss costs because cross-subsidies are more likely to be chosen by regulators during periods of rapid cost growth. Detailed data on insured loss costs and insured driver risk characteristics by Massachusetts town are used to link the cost trends more specifically to the incentive effects that arise from premium subsidies. Economic theory predicts that premium subsidies distort incentives in a variety of ways that lead to greater interest in insurance among consumers in subsidized groups and to more rapid growth in loss costs among subsidized groups. This prediction can be tested with the data available.

\section{Data by Massachusetts Town}

The data on insured loss costs and insured driver risk characteristics by town are obtained from documentation of the biennial Massachusetts regulatory hearings for territory determination. These data include actuarial estimates of the pure premiums and aggregate risk factors for each town. The available data used in our analysis span the time period 1999-2007 for territory determination filings, at 2-year intervals. In each case, the filings include four prior accident years of loss data. For example, towns are grouped into rating territories for policies issued as of January 4, 2007 based upon data reported for accident years 2001-2004, each as of 24 months development. Overall, five data sets are available for this study, reflecting loss experience for the years 1993-2004.

The analysis of town assignments to rating territories has two major elements. First, the relative loss potential of each town is estimated. Second, towns having similar estimates of loss potential are grouped into territories (Automobile Insurers Bureau of Massachusetts [AIB], 2006). Specifically,

\begin{abstract}
The estimation of each town's loss potential begins with the actual insurance experience (vehicle exposures, claim counts, loss dollars) of each town. The towns' loss cost experience is dissected into claim frequency and claim severity components and the two components are analyzed separately. This information alone is not sufficient, however, since less than complete credibility can be attributed to the actual experience of the towns. The partially credible actual data must be supplemented by additional information and/or judgments.
\end{abstract}

In the analysis of town claim frequencies, a mathematical model of frequency potential by town is constructed using data related to the 4-year insurance experience of the towns, and is used to supplement less than fully credible actual town frequency data. The model parameters and quantification of town credibilities are based on an analysis of patterns in loss experienced across towns and years (Conger, 1988).

In the analysis of town claim severities, partially credible actual town average cost data are supplemented by data from larger geographic regions (countywide and statewide data). As in the claim frequency analysis, the quantification of town credibilities is based on an analysis of patterns in loss experience across towns, counties, and years. 


\section{TABLE 6}

Massachusetts Town Data, Characteristics of Towns Receiving Subsidy in 2005

\begin{tabular}{|c|c|c|c|c|}
\hline & \multicolumn{2}{|c|}{$\begin{array}{l}\text { Subsidy Receiving } \\
\qquad(N=19)\end{array}$} & \multicolumn{2}{|c|}{$\begin{array}{l}\text { Subsidy Paying } \\
\qquad(N=341)\end{array}$} \\
\hline & Mean & S.D. & Mean & S.D. \\
\hline Pure premium index & 2.0262 & 0.5248 & 0.7267 & $0.1733^{* *}$ \\
\hline Insured exposures (PDL) & $30,346.00$ & $20,889.00$ & $9,969.00$ & $9,933.00^{* *}$ \\
\hline Traffic density & 210.10 & 59.39 & 93.56 & $60.38^{* *}$ \\
\hline BIL ACRF & 1.1150 & 0.1034 & 0.9804 & $0.0330^{* *}$ \\
\hline PDL ACRF & 1.0538 & 0.0581 & 0.9936 & $0.0255^{* *}$ \\
\hline
\end{tabular}

Note: Traffic density $=$ exposures per mile of road. ${ }^{* *}$ Indicates means for subsidized and unsubsidized towns are significantly different at the 5 percent confidence level.

Source: Authors' calculations based on data from AIB.

The result of the claim frequency and severity analysis for each town is used to calculate a loss cost (pure premium) index value for each town as a simple product. The index value expresses the town's loss potential relative to the statewide average. For example, a town index of 1.25 indicates that the per vehicle insurance loss costs for a typical driver in the town are expected to be 25 percent greater than the statewide average.

The town index procedure has been in place with few changes since the early 1980s. The initial credibility procedures were developed by William DuMouchel, a statistician at MIT (DuMouchel, 1983). As a result, the town index for each of the five coverage groups (BIL, PIP, PDL, collision and comprehensive, all at compulsory or standard deductible levels) is a best Bayesian estimate of the combined 4-year accident data for each town, normalized for other rating variables, underlying each new territory definition year. We use these town data indices in analyzing the effect of subsidies on the realized accident years 1993-2004 that underlie the territory definition years of 1999-2007.

Some of the town-to-town variation in pure premiums may be captured already by other rating variables. For example, a town with a heavy concentration of inexperienced operators will tend to exhibit a high pure premium but should not necessarily be put in a high rated territory, since the classification pricing scheme will already account for this high pure premium (because inexperienced operators are charged higher than average experienced operator rates in each territory). Therefore, the procedure removes from each town's pure premium index the effects of the mix of insured drivers by driver classification as measured by the average class rating factor (ACRF). The ACRF is a town exposure weighted average of relative pure premium by class compared to statewide. The resulting town net pure premium indices are rebalanced to unity within each coverage and provide for a normalized index that measures comparable loss costs by town.

Table 6 provides a comparison of towns that are indicated to receive subsidies and those that are indicated to pay subsidies in the territory definitions for 2005. The table shows that only 19 of the 360 towns in Massachusetts receive a subsidy. The table shows that 


\section{FIGURE 3}

BI Liability Pure Premium Index Growth

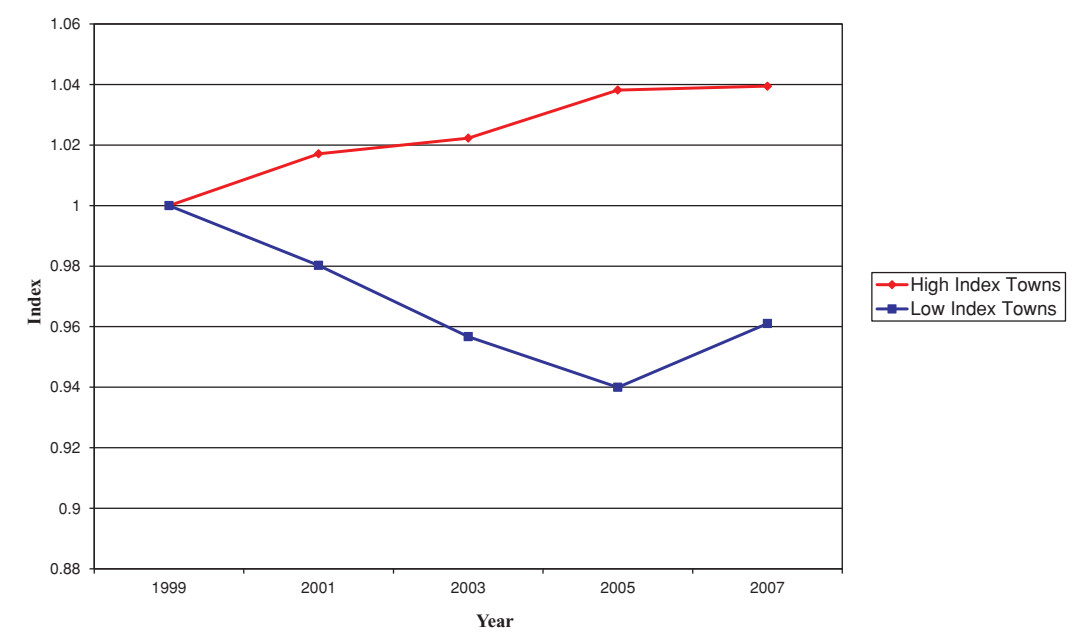

the subsidy-receiving towns tend to be larger and more densely trafficked, and have a different mix of insured drivers than the subsidy paying towns. On average, these towns also have higher pure premium index values. This is to be expected since the subsidy system is designed to provide subsidies to high-cost towns.

\section{Cost Growth by Town}

Because (by design) high-cost towns receive premium subsidies, a comparison of loss cost levels across subsidy-receiving and subsidy-paying towns will not provide reliable evidence of the impact of subsidies on insurance costs. To provide a test of the relationship between subsidies and insurance costs, our analysis of the town-level data examines the growth rates of auto insurance cost measures (percentage change from one year to the next).

To provide a preliminary look at the empirical relationships, Figures 3 and 4 compare trends in pure premium growth in the underlying accident year data for high-cost and low-cost towns over the territory definition years 1999-2007 for BIL and PDL insurance coverages, respectively. The data are grouped into high-cost and low-cost with classifications based on each town's overall pure premium index in 1999, using a value of 1.20 or greater to indicate high cost and a value of 1.00 or lower to indicate low cost. Only towns above (or below) the cutoff values in every year of the sample period are included in the figures. The averages for each group of towns are weighted by the number of insured exposures in each town. The data are normalized by setting the 1999 pure premium index for each coverage and each group of towns equal to 1.00, to facilitate comparisons in the average annual growth rates over time.

The figures show a clear upward trend in pure premiums among high-cost towns and a mirroring decrease in low-cost towns as the overall average is about 1.00 . The greater growth in the pure premium index among towns that were high cost in 1999 is consistent with the hypothesis that subsidies positively affect loss cost growth. 


\section{FigURE 4}

\section{PD Liability Pure Premium Index Growth}

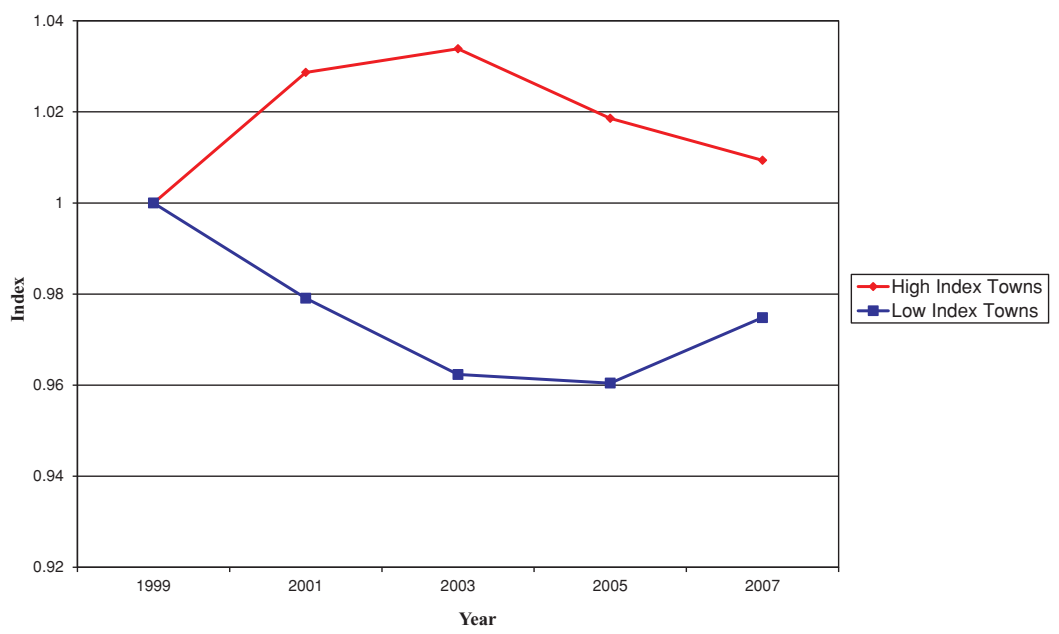

\section{Regression Analysis}

To further explore the relationship between price subsidies and changes in loss costs, simple regression models of the period-to-period changes in pure premiums are estimated. The pure premium regression model takes the following form:

$$
\begin{aligned}
\operatorname{Chg}\left(\text { PP }_{i t}\right)= & \beta_{0}+\beta_{1}\left(\text { Subsid }_{i t-\tau}\right)+\beta_{2}\left(\text { Ever-Subsidized }_{i}\right)+\beta_{3}\left(\text { PP }_{i t-1}\right)+\beta_{4}\left(\text { Boston }_{i}\right) \\
& +\delta\left(\text { Chg }_{i t}\right)+T_{t}+\varepsilon_{i t}
\end{aligned}
$$

where Chg denotes percentage biennial change, subscript $i$ denotes town and $t$ denotes year, and $P P_{i t}$ is the pure premium index for town $i$ in year $t$. The biennial change in the average pure premium index for each town is modeled as depending on the receipt of subsidy in the earliest year during which the loss data were generated (Subsidy $\left.y_{i t-\tau}\right)$, after allowing for unspecified differences between Boston-area towns and other towns $\left(\right.$ Boston $\left._{i}\right)$, and after controlling for changes in other relevant characteristics $\left(X_{i t}\right)$ of each town. ${ }^{24}$ An indicator variable set equal to one, if the town was ever assigned to a territory that received a subsidy during 1999-2007 (Ever-Subsidized ${ }_{i}$ ), is also included to control

\footnotetext{
${ }^{24}$ Because we have a large number of towns and only a small number of years in the town-level data set, we include these two indicators of time-invariant town characteristics rather than including a full set of town fixed effects. Inclusion of town fixed effects appears to substantially reduce variation in the data set and leads to implausibly large or implausibly small estimates of the impact of subsidies for some components of the pure premium. Specifically, estimates of the impact of subsidies on BIL and PDL pure premiums remain similar, although impact on PDL becomes statistically significant (10 percent confidence level). Estimates of subsidy impact on COLL become larger but remain statistically insignificant. Estimates of subsidy impact on PIP are larger by several orders of magnitude while estimates for COMP become large and negative, and in both cases are statistically significant.
} 
for unspecified differences between subsidy-receiving towns and other towns (including the possibility that such towns inherently experience higher pure premium growth). The lagged value of the pure premium index $\left(P P_{i t-1}\right)$ is included in the model to allow for the tendency for loss costs to regress toward the mean. Year indicators $T_{t}$ are included to allow for loss shocks that are common to all towns in a year. The term $\varepsilon_{i t}$ is a stochastic error term. In estimating the model standard errors are corrected for heteroskedasticity and for correlation within each town across years.

The hypothesis to be tested is that pure premium growth is positively related to the receipt of a subsidy in the years in which the loss data are generated. We obtain the subsidy status and percentage subsidy received by town and year by matching each town to its assigned territory in the year which the underlying loss data were generated. For those towns receiving a subsidy, the subsidy percent is measured as the difference between the true cost-based premium and the regulated premium for the town, divided by the cost-based premium; the subsidy percent variable is set equal to zero in towns that do not receive a subsidy. The period indicator for the subsidy variable is denoted by $t-\tau$ to make clear that the relevant period is not the previous territory definition year but rather the years in which the current pure premium data were generated. For example, the 2007 pure premium index is based on loss data from 2001 to 2004 . Because the loss data years overlap for our territory definition years, we use the subsidy values generated from the earliest year of the loss data (using the 2001 subsidy percent to analyze the impact on 2007). ${ }^{25}$

The model is estimated separately for each of the five auto insurance coverages. The control variables included in the models are the percentage change in the ACRF, the percentage change in the number of cars insured for compulsory coverages, and the change in traffic density in each town. These variables are measured using data from the most recent loss data year; for example, 2004 data are used for the 2007 pure premium index year.

A second set of models analyzes changes in the ACRF. These models provide a test of the hypothesis that subsidies lead to greater entry of high-risk drivers into the insurance pool. The model estimated is

$$
\begin{aligned}
\operatorname{Chg}\left(A C R F_{i t}\right)= & \beta_{0}+\beta_{1}\left(\text { Subsid }_{i t-\tau}\right)+\beta_{2}\left(\text { Ever-Subsidized }_{i}\right)+\beta_{3}\left(\text { ACRF }_{i t-1}\right) \\
& +\beta_{4}\left(\text { Boston }_{i}\right)+\delta\left(\text { Chg }_{i t}\right)+T_{t}+\varepsilon_{i t}
\end{aligned}
$$

using the same notation defined for the previous model. The ACRF models are estimated for each of the five automobile insurance coverages separately. Changes in the ACRF may reflect either changes in the demographics of a town or changes in the characteristics of insured drivers in the town (irrespective of changes in town demographics). To capture changes in demographic characteristics that may lead to changes in the propensity to purchase insurance, the control variables $\left(X_{i t}\right)$ include the change in the average age of cars and the change in the percentage of luxury cars registered, as well as the change

\footnotetext{
${ }^{25}$ Results are similar when subsidies are averaged for the first 2 years of loss data (e.g., using the average of 2001 and 2002 for 2007).
} 


\section{TABLE 7}

Summary Statistics Annual Town-Level Data, Massachusetts 2001-2007 Index Years

\begin{tabular}{|c|c|c|c|}
\hline Variable & $N$ & Mean & S.D. \\
\hline Pct change BIL PP index & 1,439 & 0.0006 & 0.1588 \\
\hline Pct change PIP PP index & 1,439 & -0.0191 & 0.1351 \\
\hline Pct change PDL PP index & 1,440 & -0.0048 & 0.0524 \\
\hline Pct change COLL PP Index & 1,439 & -0.0056 & 0.0635 \\
\hline Pct change COMP PP index & 1,440 & 0.0210 & 0.0963 \\
\hline Lag BIL PP Index & 1,440 & 0.7476 & 0.4503 \\
\hline Lag PIP PP Index & 1,440 & 0.7203 & 0.5688 \\
\hline Lag PDL PP index & 1,440 & 0.8404 & 0.2344 \\
\hline Lag COLL PP index & 1,440 & 0.8777 & 0.2644 \\
\hline Lag COMP PP index & 1,440 & 0.8516 & 0.3896 \\
\hline Pct change BIL ACRF index & 1,440 & -0.0036 & 0.0175 \\
\hline Pct change PIP ACRF index & 1,440 & -0.0048 & 0.0196 \\
\hline Pct change PDL ACRF Index & 1,440 & -0.0020 & 0.0130 \\
\hline Pct change COLL ACRF Index & 1,440 & -0.0018 & 0.0177 \\
\hline Pct change COMP ACRF index & 1,440 & -0.0011 & 0.0153 \\
\hline Lag BIL ACRF Index & 1,440 & 0.9951 & 0.0386 \\
\hline Lag PIP ACRF index & 1,440 & 0.9889 & 0.0463 \\
\hline Lag PDL ACRF index & 1,440 & 1.0000 & 0.0266 \\
\hline Lag COLL ACRF index & 1,440 & 0.9982 & 0.0336 \\
\hline Lag COMP ACRF index & 1,440 & 0.9974 & 0.0452 \\
\hline Subsidy indicator (lagged) & 1,440 & 0.0688 & 0.2531 \\
\hline Subsidy percent (lagged) & 1,440 & 0.0094 & 0.0453 \\
\hline Pct change luxury cars & 1,433 & 0.1350 & 0.2414 \\
\hline Pct change mean age of car & 1,425 & 0.0391 & 0.1023 \\
\hline Pct change traffic density & 1,440 & 0.0310 & 0.0454 \\
\hline Boston dummy & 1,440 & 0.2194 & 0.4140 \\
\hline Pct change exposures & 1,440 & 0.0399 & 0.0348 \\
\hline
\end{tabular}

Source: Data on PP Indices, ACRF Indices, subsidies, traffic density and insured exposures from AIB; data on luxury cars and mean car age from Massachusetts Division of Motor Vehicles.

in traffic density, for each town. ${ }^{26}$ As in the pure premium models, we also allow for unspecified differences between Boston-area and other towns, and between subsidyreceiving towns and other towns. The model also includes the lagged ACRF value to control for regression to the mean.

\footnotetext{
${ }^{26}$ Data on the town-level control variables were obtained from the Commonwealth of Massachusetts Department of Revenue, Municipal Data Bank reports.
} 


\section{TABLE 8}

Regression Analysis of Growth in Pure Premiums by Town, Index Years 2001-2007

\begin{tabular}{|c|c|c|c|c|c|}
\hline \multicolumn{6}{|c|}{ Dependent Variable $=\mathrm{PP} \operatorname{Index}(t) / \mathrm{PP} \operatorname{Index}(t-1)-1$} \\
\hline Explanatory Variable & BIL PP & PIP PP & PDL PP & COLL PP & COMP PP \\
\hline \multirow[t]{2}{*}{ Subsidy percent $(t-\tau)$} & $0.509^{* * *}$ & $0.287^{*}$ & -0.021 & 0.039 & $0.255^{* *}$ \\
\hline & 3.186 & 1.647 & -0.620 & 0.783 & 2.303 \\
\hline \multirow[t]{2}{*}{ Ever-subsidized indicator } & $0.080^{* * *}$ & $0.065^{* * *}$ & $0.018^{* * *}$ & $0.031^{* * *}$ & 0.005 \\
\hline & 4.671 & 4.082 & 4.211 & 4.791 & 0.500 \\
\hline \multirow[t]{2}{*}{ Pure premium $(t-1)$} & $-0.109^{* * *}$ & $-0.036^{* *}$ & -0.011 & $-0.041^{* * *}$ & $-0.078^{* * *}$ \\
\hline & -4.208 & -2.207 & -1.109 & -3.205 & -5.230 \\
\hline \multirow[t]{2}{*}{ Pct change exposures } & 0.008 & 0.065 & -0.050 & -0.166 & -0.023 \\
\hline & 0.035 & 0.404 & -0.631 & -1.171 & -0.157 \\
\hline \multirow[t]{2}{*}{ Pct change density } & $0.352^{* *}$ & $0.267^{* *}$ & 0.063 & 0.064 & -0.077 \\
\hline & 2.284 & 2.485 & 1.358 & 1.392 & -1.073 \\
\hline \multirow[t]{2}{*}{ Boston dummy } & -0.005 & $0.017^{*}$ & -0.005 & 0.004 & 0.008 \\
\hline & -0.379 & 1.892 & -1.289 & 0.728 & 1.356 \\
\hline \multirow[t]{2}{*}{ Pct change BIL ACRF } & 0.204 & & & & \\
\hline & 0.288 & & & & \\
\hline \multirow[t]{2}{*}{ Pct change PIP ACRF } & & -0.254 & & & \\
\hline & & -0.666 & & & \\
\hline \multirow[t]{2}{*}{ Pct change PDL ACRF } & & & -0.121 & & \\
\hline & & & -0.666 & & \\
\hline \multirow[t]{2}{*}{ Pct change COLL ACRF } & & & & 0.497 & \\
\hline & & & & 1.361 & \\
\hline \multirow[t]{2}{*}{ Pct change COMP ACRF } & & & & & 0.270 \\
\hline & & & & & $0.078^{* * *}$ \\
\hline \multirow[t]{2}{*}{ Intercept } & $0.043^{*}$ & $-0.062^{* * *}$ & -0.009 & 0.024 & $1.1980 .078^{* * *}$ \\
\hline & 1.820 & -4.490 & -0.894 & 1.463 & 5.572 \\
\hline Year fixed effects & Yes & Yes & Yes & Yes & Yes \\
\hline$R^{2}$ & 0.043 & 0.079 & 0.060 & 0.070 & 0.082 \\
\hline$N$ & 1,439 & 1,439 & 1,440 & 1,439 & 1,440 \\
\hline
\end{tabular}

Note: $T$-statistics appear below the coefficient estimates. ${ }^{* * *}$ Indicates statistically significant at the 1 percent confidence level, ${ }^{* *}$ indicates the 5 percent confidence level, and ${ }^{*}$ indicates the 10 percent level; all are two-sided tests.

Estimation Results

Summary statistics for the variables included in the Massachusetts town regression models are reported in Table 7, and the estimation results are presented in Tables 8 and 9. Table 8 reports estimates for the pure premium models, and those for the ACRF 


\section{TABLE 9}

Regression Analysis of Growth in ACRF by Town Territory Assignment Years 2001-2007

\begin{tabular}{lccccc}
\hline \multicolumn{5}{c}{ Dependent Variable $=$ ACRF Index $(t)$ / ACRF Index $(t-1)-1$} \\
\hline Explanatory Variable & BIL ACRF & PIP ACRF & PDL ACRF & COLL ACRF & COMP ACRF \\
\hline Subsidy percent $(t-\tau)$ & $0.173^{* * *}$ & $0.216^{* * *}$ & $0.102^{* * *}$ & $0.108^{* * *}$ & $0.073^{* * *}$ \\
Ever-subsidized indicator & 6.176 & 5.862 & 6.422 & 5.327 & 4.965 \\
& $0.006^{* * *}$ & $0.011^{* * *}$ & $0.002^{* * *}$ & $0.004^{* * *}$ & $0.005^{* * *}$ \\
& 4.459 & 5.584 & 2.738 & 4.030 & 5.308 \\
ACRF( $t-1)$ & $-0.085^{* * *}$ & $-0.106^{* * *}$ & $-0.084^{* * *}$ & $-0.162^{* * *}$ & $-0.121^{* * *}$ \\
& -4.368 & -4.359 & -4.702 & -4.105 & -5.284 \\
Pct change density & -0.005 & 0.005 & -0.013 & $-0.032^{* *}$ & 0.001 \\
& -0.384 & 0.396 & -1.275 & -2.443 & 0.048 \\
Boston dummy & $-0.004^{* * *}$ & $-0.004^{* * *}$ & $-0.003^{* * *}$ & $-0.003^{* * *}$ & $-0.002^{* *}$ \\
Pct change luxury cars & -3.912 & -3.798 & -3.603 & -2.953 & -2.550 \\
& 0.004 & 0.003 & 0.003 & -0.005 & 0.004 \\
Pct change mean car age & 1.582 & 0.994 & 1.624 & -1.495 & 1.243 \\
& -0.001 & 0.000 & -0.002 & $-0.006^{*}$ & -0.001 \\
Intercept & -0.336 & -0.019 & -0.710 & -1.764 & -0.291 \\
& $0.075^{* * *}$ & $0.093^{* * *}$ & $0.078^{* * *}$ & $0.155^{* * *}$ & $0.111^{* * *}$ \\
Year fixed effects & 3.944 & 3.940 & 4.420 & 3.963 & 4.850 \\
$R^{2}$ & Yes & Yes & Yes & Yes & Yes \\
$N$ & 0.287 & 0.331 & 0.202 & 0.180 & 0.225 \\
\hline N & 1,418 & 1,418 & 1,418 & 1,418 & 1,418 \\
\hline
\end{tabular}

Note: $T$-statistics appear below the coefficient estimates. ${ }^{* * *}$ Indicates statistically significant at the 1 percent confidence level, ${ }^{* *}$ indicate the 5 percent confidence level, and ${ }^{*}$ indicate the 10 percent level; all are two-sided tests.

models are reported in Table 9. The models are estimated using 2001-2007 data due to the inclusion of lagged variables.

The results of estimating changes in pure premium by town are reported in Table 8 . The estimates show a positive relationship between larger subsidy percents and pure premium growth for three of the five coverages. The estimated effects of larger subsidies are significant at the 1 percent confidence level for BI liability, and at the 5 percent confidence level for comprehensive pure premium growth. There are marginally significant effects (at the 10 percent confidence level) of larger subsidies on pure premium growth in PIP coverage. The effect of larger subsidies on pure premium growth is very close to zero and statistically insignificant in PD liability and collision coverage.

The coefficient estimates on the ever-subsidized indicator are significant and positive for four of the five coverages (all except comprehensive), consistent with the idea that 
towns in subsidized territories have inherently higher pure premium growth than other towns. The lagged value of the pure premium is significant and negative for four of the five coverages (all except PD liability), consistent with regression to the mean. Increases in traffic density are significantly and positively related to pure premium growth for BI liability and PIP, but not for other coverages. Most other control variables are statistically insignificant in all of the coverage models.

The estimation results relating town subsidies to changes in ACRF are reported in Table 9. The estimates support the hypothesis that previous subsidies received are significantly related to changes in a town's ACRF. The estimated effect is significant at the 1 percent confidence levels for all five coverages and is greatest in magnitude for BI liability and PIP, even after controlling for changes in other characteristics of towns' auto insurance environments. Consistent with the predictions of theory, these estimates suggest that insurance decisions are sensitive to the receipt of premium subsidies, with subsidies leading to a greater proportion of high-risk drivers in the insurance pool.

\section{CONCLUSION}

Insurance rate regulation in the United States had its origins in the twin concerns of excessive monopoly pricing on the one hand and potential insolvency from inadequate pricing and capital commitment on the other hand. Under the state-by-state regulatory scheme in the United States, rate regulation evolved to address local concerns such as price levels for high-risk insurance consumers, risk classifications (and price differentials) based upon socially unacceptable or controversial characteristics of insurance consumers, and mandatory levels of coverage. That evolution has led to a patchwork of state-specific laws and regulations with varying levels of stringency and enforcement.

Nowhere is this variety more prominent than in private passenger automobile insurance, where rating classifications and regulatory restraints have promoted cross-subsidies among the insured populations. The most common of subsidy-inducing regulatory actions are (1) restriction of risk classification plans and (2) restrictions on pricing for allowed classification. The strict regulation of classification and pricing of Massachusetts private passenger automobile insurance during 1978-2007 serves here as a test of whether the reduction in efficiency from these cross-subsidy-providing restrictions result in excessive cost growth.

Two approaches were taken to study the potential loss cost reaction to the Massachusetts cross-subsidies. The first approach compared Massachusetts costs with countrywide costs, after controlling for demographic, regulatory, and liability coverage levels. Loss cost levels that were 29 percent above the expected level were found for Massachusetts during the 1978-1998 period, when premiums charged were those fixed by the state. A second approach considered changing cost levels within Massachusetts by studying town-level data and comparing towns that were subsidy providers with those that were subsidy receivers. Subsidy data for 1999-2007, with underlying accident year data for 1993-2004, showed a positive (relative) growth in loss costs and an increasing proportion of high-risk drivers for towns that were subsidy receivers. These results are in line with the theory of underlying incentives for adverse selection and moral hazard created by premium subsidies. 


\section{RefERENCES}

Automobile Insurers Bureau of Massachusetts, Various Years, Actuarial Notice-2: Subsidies in the Rates, Boston, MA.

Automobile Insurers Bureau of Massachusetts, 2006, AIB Recommendations for 2007 Private Passenger Automobile Insurance Territory Definitions, MA DOI Docket R200603, May 15.

Bertrand, M., E. Duflo, and S. Mullainathan, 2004, How Much Should We Trust Differences-in-Differences Estimates, Quarterly Journal of Economics, 119(1): 249-275.

Blackmon, B. G., Jr., and R. Zeckhauser, 1991, Mispriced Equity: Regulated Rates for Auto Insurance in Massachusetts, American Economic Review, 81: 65-69.

Brockett, P. L., and L. L. Golden, March 2007, Biological and Psychobehavioral Correlates of Credit Scores and Automobile Insurance Loss: Toward an Explication of Why Credit Scoring Works, Journal of Risk and Insurance 74(1): 22-63.

Burnes, N. S., July 16, 2007, Opinion, Findings, and Decision on the Operation of Competition in Private Passenger Motor Vehicle Insurance in 2008, Division of Insurance Docket No. R2007-03, Boston, MA.

Conger, R. F., 1988, The Construction of Automobile Rating Territories in Massachusetts, Proceedings of the Casualty Actuarial Society, 71(Part 1): 1-74.

Cummins, J. D., and S. Tennyson, 1992, Controlling Automobile Insurance Costs, Journal of Economic Perspectives, 6(2): 95-115.

Cummins, J. D., and S. Tennyson, 1996, Moral Hazard in Insurance Claiming: Evidence From Automobile Insurance, Journal of Risk and Uncertainty 12(1): 29-50.

Dahlby, B., 1983, Adverse Selection and Statistical Discrimination: An Analysis of Canadian Automobile Insurance, Journal of Public Economics, 20: 121-130.

Dahlby, B., 1992, Testing for Asymmetric Information in Canadian Automobile Insurance, in: G. Dionne, ed., Contributions to Insurance Economics (Boston: Kluwer Academic Publishers).

Danzon, P. M. and S. E. Harrington, 2001, Workers' Compensation Rate Regulation: How Price Controls Increase Costs, Journal of Law and Economics, 44: 1-36.

Derrig, R. A., D. J. Johnston, and E. A. Sprinkel, Fall 2006, Auto Insurance Fraud: Measurements and Efforts to Combat it, Risk Management and Insurance Review, 9(2): 109130.

Derrig, R. A., 1997, Auto Property Damage Cost Containment-A Billion Dollar Decade of Progress in Massachusetts, Automobile Insurers Bureau of Massachusetts Cost Containment and Fraudulent Claims Payment Filing, Docket R97-37, July, Division of Insurance, Boston, MA.

Derrig, R. A., 1993, Price Regulation in US Automobile Insurance: A Case Study of Massachusetts Private Passenger Automobile Insurance 1978-1990, Geneva Papers on Risk and Insurance, 18: 158-173.

DuMouchel, W. H., 1983, The Massachusetts Automobile Insurance Classification Scheme, The Statistician, 32: 69-81.

Finger, R. J., 2006, Risk Classification, in: Foundations of Casualty Actuarial Science, 4th edition (Arlington, VA: Casualty Actuarial Society). 
Grace M. F., R. W. Klein, and R. D. Phillips, 2002, Auto Insurance Reform: Salvation in South Carolina, in: J. D. Cummins, ed., Deregulating Property-Liability Insurance (Washington, DC: Brookings Institution Press), pp. 148-194.

Harrington, S. E., 1990, The Relationship Between Voluntary and Involuntary Market Rates: Regulation in Automobile Insurance, Journal of Risk and Insurance, 57: 9-27.

Harrington, S. E., 2002, Effects of Prior Approval Rate Regulation of Auto Insurance, in: J. D. Cummins, ed., Deregulating Property-Liability Insurance (Washington, DC: Brookings Institution Press), pp. 285-314.

Harrington, S. E., and P. M. Danzon, 2000, Rate Regulation, Safety Incentives, and Loss Growth in Workers' Compensation Insurance, Journal of Business, 73: 569-595.

Harrington, S. E., and H. I. Doerpinghaus, 1993, The Economics and Politics of Automobile Insurance Rate Classification, Journal of Risk and Insurance, 60: 59-84.

Johnston, D. J., 2009, The Community Insurance Fraud Initiative (CIFI): A Five Year Retrospective, Automobile Insurers Bureau of Massachusetts and Insurance Fraud Bureau of Massachusetts, Boston, MA.

Picard, P., 1996, Auditing Claims in the Insurance Market with Fraud: The Credibility Issue, Journal of Public Economics, 63: 27-56.

Regan, L., M. A. Weiss, and S. Tennyson, 2008, The Relationship Between Auto Insurance Rate Regulation and Insured Loss Costs: An Empirical Analysis, Journal of Insurance Regulation 27(1): 23-46.

Rottenberg, S., 1989, The Cost of Regulated Pricing: A Critical Analysis of Auto Insurance Premium Rate-Setting in Massachusetts, Pioneer Institute for Public Policy Research, Boston.

Shavell, S., 1982, On Liability and Insurance, Bell Journal of Economics, 13(1): 120-132.

Stone, J. M., 1977, Opinion and Findings on the Operation of Competition Among Motor Vehicle Insurers (Boston, MA: Massachusetts Division of Insurance).

Tennyson, S., 1997, The Impact of Rate Regulation on State Automobile Insurance Markets, Journal of Insurance Regulation, 15: 502-523.

Tennyson, S., M. Weiss, and L. Regan, 2002, Automobile Insurance Regulation: The Massachusetts Experience, in: J. D. Cummins, ed., Deregulating Property-Liability Insurance: Restoring Competition and Increasing Market Efficiency (Washington, DC: AEI-Brookings Joint Center for Regulatory Studies).

Weisberg, H. I., and R. A. Derrig, 1991, Fraud and Automobile Insurance: A Report on the Baseline Study of Bodily Injury Claims in Massachusetts, Journal of Insurance Regulation, 9: 497-541.

Weisberg, H. I., and R. A. Derrig, 1992, Massachusetts Automobile Bodily Injury Tort Reform, Journal of Insurance Regulation, 10, 384-440.

Weiss, M., S. Tennyson, and L. Regan, 2010, The Effects of Automobile Insurance Rate Regulation on Loss Costs and Claim Frequency: An Empirical Analysis, Journal of Risk and Insurance, 77: 597-624.

Yelen, S., 1993, Withdrawal Restrictions in the Automobile Insurance Market, Yale Law Journal, 102: 1431-1455. 